\title{
Toward an ecological aesthetic
}

\author{
Frederick Steiner ${ }^{1} \mathbb{0}$
}

Received: 18 September 2018 / Accepted: 4 December 2018 / Published online: 2 January 2019

(c) Springer Nature Singapore Pte Ltd. 2018, corrected publication 2019

\begin{abstract}
The visual appearance of built environments reflects the values of their inhabitants. As a result, socio-ecological practice needs to consider aesthetics. Ecological aesthetics involve sensual connections to natural and cultural processes. The Sustainable SITES Initiative provides an example of the application of ecosystem services that may result in such an aesthetic. Entropy suggests everything moves from order to disorder. Negentropy reverses that tendency. Design and planning may be viewed as tools for negentropy and aesthetics as a visual manifestation of such interventions.
\end{abstract}

Keywords Ecological aesthetics $\cdot$ Ecosytem services $\cdot$ Sustainable sites $\cdot$ Negentropy

\section{Aesthetics and socio-ecological practice}

Aldo Leopold is well known for his advocacy of a "land ethic" but less so for his ideas about a "land esthetic" (1949). "The landscape of any farm is the owner's portrait of himself," he wrote (1939, p. 263). More recently, the American poet Wendell Berry tweeted on June 24, 2018, "A good farm is recognized as good partly by its beauty." By extension beyond the farm, every place reflects its culture. What we see sums up what is. Leopold's and Berry's observations apply to urban neighborhoods and suburban shopping malls from Las Vegas to Xi'An. What we currently see in much of the USA is a culture driven by commerce and short-term goals and resulting in considerable chaos and disorder. Large swaths of the planet display similar tendencies.

One can imagine an alternative: a culture assembled through ecological knowledge and wisdom. Such a culture would move from disorder to order, that is, reducing entropic tendencies. This would be an outcome of socio-ecological practice. At its heart, such practice requires a new way of understanding Leopold's "wounds" of the world (1966, p. $165)$, healing those scars, and creating new lives and new landscapes. This demands an ecological aesthetic.

Ecological aesthetics involve sensual connections to natural and cultural processes. Such connections elevate our

Frederick Steiner

fsteiner@design.upenn.edu

1 University of Pennsylvania School of Design, 102 Meyerson Hall, 210 South 34th Street, Philadelphia, PA 19104, USA awareness of the socio-ecological interrelationships in our surroundings and enable us to adapt to change based on that knowledge. As Dewey (1934) noted, aesthetics enhance and intensify everyday experiences (see, for instance, Bourassa 1991). Dewey grounded his ideas in the biological sensory exchange between people and their environments: “...An experience is a product, one might almost say bi-product, of continuous and cumulative interaction of an organic self with the world. There is no other foundation upon which esthetic theory and criticism can build" (1934, p. 220).

To produce places that connect with people and nature, we must learn how to read landscapes. Anne Whiston Spirn noted that this requires a knowledge of the "language of landscape" that enables us to understand the "deep context" of our surroundings (Spirn 1998). That context is grounded in the fundamental climatic-geologic-hydrologic processes that shape territories. We humans exert such a dominant influence on those processes globally that we have entered a new geologic era of our making-The Anthropocene. This era adds another layer of responsibility regarding our actions and our inactions.

We need to take walks and to ask what is under our feet. Rocks and soils and river basins have histories. We should learn those histories. Where does our water come from? Is the source dependable? What is the annual rainfall? Look at the clouds; feel the wind. How does the weather change through the day; through the year? How might climate change affect water flows and volume?

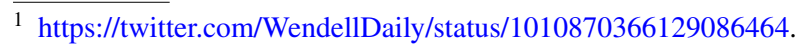


We need to look around and see what else is alive. What plants grow in our neighborhood? Are they native or imported? The birds: do they migrate by seasons or stay put? Where do these flying creatures eat and mate? What other animals live around us? How about honey bees? Bees seem to like urban living. And us: How do we organize our communities, cities, and regions? What are our histories, our laws, our institutions? What do we believe in?

Beyond asking questions, we should explore what others have observed and document our landscape readings through maps, diagrams, photographs, drawings, and prose. Geographers and historians, soil scientists and botanists, and artists and engineers have complied different readings of the same place. We can learn much from boundaries: property lines and jurisdictions. Utilities and roadways connect places and create their divisions.

For most places on our planet, a bounty of information and knowledge exists about human and natural phenomena and process. What we lack is the wisdom, the ecological practical wisdom or ecophronesis as Wei-Ning Xiang calls it (2016, p. 55), to use that information and knowledge to shape communities that are safer, healthier, more productive, and beautiful. "Eco" comes from the Greek oikos, house or household, and phrónessis is the virtue of practical wisdom (Austin 2018). As members of Homo sapiens and to live up to our sapient quality, we should strive to become a truly wise species. Such wisdom will be reflected in our self-portraits.

This is hardly a new idea. Twenty centuries ago, the Roman architect and engineer Marcus Vitruvius Pollio based his treatise, De architectura (On Architecture), on a broad understanding of disparate sciences. "Architecture is a science arising out of many other sciences," Vitruvius wrote (Granger 1931). He suggested that buildings should be designed from a careful understanding of their sites. Beauty was also important to Vitruvius and is part of his triad of building qualities - being solid, useful, and beautiful (firmitas, utilitas, venustas). He also extended these principles to city planning.

Leopold offered his own triad in A Sand County Almanac: "A thing is right when it tends to preserve the integrity, stability, and beauty of the biotic community" (1949, p. 242). He added, "It is wrong when it tends otherwise" (Ibid., p. 242). For Leopold, ethics and aesthetics should have equal standing with what was "economically efficient." Like Vitruvius, Leopold favored stability or being solid. The two have beauty in common too, but for Leopold, it was grounded in the biotic community. As biological creatures, we are part of that community.

The survival of species depends on beauty. Yale ornithologist Richard Prum (2017) revived Charles Darwin's "forgotten" theory about how beauty influences mate selection. Darwin explored how mating preferences are dictated by "the taste for the beautiful." How we evolved to desire beauty has attracted the attention of neuroscientists, such as Anjan Chatterjee who observed: "strong evolutionary forces selected minds that find some places more beautiful than others" (2014, p. 48).

\section{Negentropy: from Charles Darwin to Patrick Geddes and lan McHarg}

Darwinian ideas have influenced applications of biology in town planning and landscape design. Educated as a biologist, the town planning pioneer Patrick Geddes was greatly affected by Darwin's writings, but as advanced and interpreted by Thomas Henry Huxley. An advocate of evolution, Huxley was Geddes' teacher at the Royal School of Mines in London. Geddes advocated the proposition that organisms (including humans) participate in their own evolution (Batty and Marshall 2017). For Geddes, town planning was an instrument for humans to participate in their own evolution (Steiner and McSherry 2017). As Avigail Sachs noted, "Geddes argued that the logic of biological systems could be adapted to understand and improve social systems" (2018, p. 11).

The landscape architect and planner McHarg (1969) was also guided by Darwin, but even more so by Harvard scientist and philosopher Lawrence Henderson. Henderson's theory of mutual adaptation inspired McHarg's advocacy of the methodical, ecological reading of a place as a means to reveal what he called its "intrinsic suitabilities," which he perceived as a means to redirect "time's arrow" and create negentropy (1969, see also Schrödinger 1944 and Prigogine and Stengers 1984). Opportunities and constraints result from McHarg's approach that can be used to plan and design communities and regions. That is; a careful reading of a landscape can reveal opportunities for certain land uses to occur while displaying constraints for other uses. McHarg's method is especially effective in identifying places that are dangerous, unsafe, and unhealthy for people to live. Through such an approach, the resulting settlements emerge from ecological knowledge as applied through ecological wisdom.

Ecological design and planning, then, provide a way for us to participate in our own evolution through reading landscapes to help us fit uses to specific places. The results would reflect the beauty of the biotic community and be stable, or at least adaptable to change. We human beings would thus be indeed empowered to participate in our own evolution by adapting to change. According to Austin, "adaptation goes beyond coping strategies, and requires rethinking who we are, what the virtuous life consists in, and how our institutions should be structured" (2018, p. 1012). 
Table 1 Ecosystem services and SITES

Ecosystem services are goods and services of direct or indirect benefit to humans that are produced by ecosystem processes that involve the interactions of living elements, such as vegetation and soil organisms, and nonliving elements such as bedrock, water, and air

The Sustainable SITES Initiative has referenced various existing versions of ecosystem services to create the following list of those that a site can protect or regenerate through sustainable land development and management practices

\section{Global climate regulation}

Maintaining balance of atmospheric gases at historic levels, creating breathable air, and sequestering greenhouse gases

\section{Local climate regulation}

Regulating local temperature, precipitation, and humidity through shading, evapotranspiration, and windbreaks

\section{Air and water cleansing}

Removing and reducing pollutants in air and water

Water supply and regulation

Storing and providing water within watersheds and aquifers

\section{Erosion and sediment control}

Retaining soil within an ecosystem, preventing damage from erosion and siltation

\section{Hazard mitigation}

Reducing vulnerability to damage from flooding, storm surge, wildfire, and drought

\section{Pollination}

Providing pollinator species for reproduction of crops or other plants

\section{Habitat functions}

Providing refuge and reproduction habitat to plants and animals, thereby contributing to conservation of biological and genetic diversity and evolutionary processes

\section{Waste decomposition and treatment}

Breaking down waste and cycling nutrients

Human health and well-being benefits

Enhancing physical, mental, and social well-being as a result of interaction with nature

Food and renewable nonfood products

Producing food, fuel, energy, medicine, or other products for human use

\section{Cultural benefits}

Enhancing cultural, educational, aesthetic, and spiritual experiences as a result of interaction with nature

(Lady Bird Johnson Wildflower Center et al. 2014)

\section{SITES for ecological aesthetics and negentropy}

To be effective, ecological design and planning need concrete measures and methods. The ecosystem services concept offers a framework for measurement, and the Sustainable SITES Initiative presents a method. A careful understanding and application of ecological services in site design and planning would help foster an aesthetic as conceived by Leopold grounded in ecology.

Similar to the U.S. Green Building Council's Leadership in Energy and Environmental Design, or LEED, rating program for buildings, the Sustainable SITES Initiative was initiated in 2005 as an effort to create a green rating system for designed outdoor spaces. Integral to the initiative is the very concept of ecosystem services (Windhager et al. 2010) (Table 1). As Woodruff and BenDor observe: "Ecosystem services are a powerful tool for land-use and environmental planning, which can help decision makers better understand the tradeoffs between different development scenarios" (2016, p. 90).

SITES delineates a process to assess the sustainability performance of designed landscapes. The system can be used for projects on sites with or without buildings, such as parks, botanic gardens, university campuses, plazas, waterfronts, cemeteries, and streets. The system involves a series of prerequisites that must be met and credits that can be achieved. Combined, the prerequisites and credits result in a score to determine a level of certification. The prerequisites and credits address the site context; a pre-design assessment; the use of water, soil, vegetation, materials, and human health and well-being in design; construction; operations and maintenance; and education and performance. Credits can also be earned for innovation in design.

SITES was tested with over 150 pilot projects, so it was grounded in experience before its designers turned it over to Green Business Certification Inc. (GBCI) in 2016. GBCI is an American organization that provides third-party credentialing and verification for several green building systems 
Fig. 1 Spiral Jetty by Robert Smithson, Great Salt Lake, Utah, USA. Photographed by Frederick Steiner on February 9, 2018

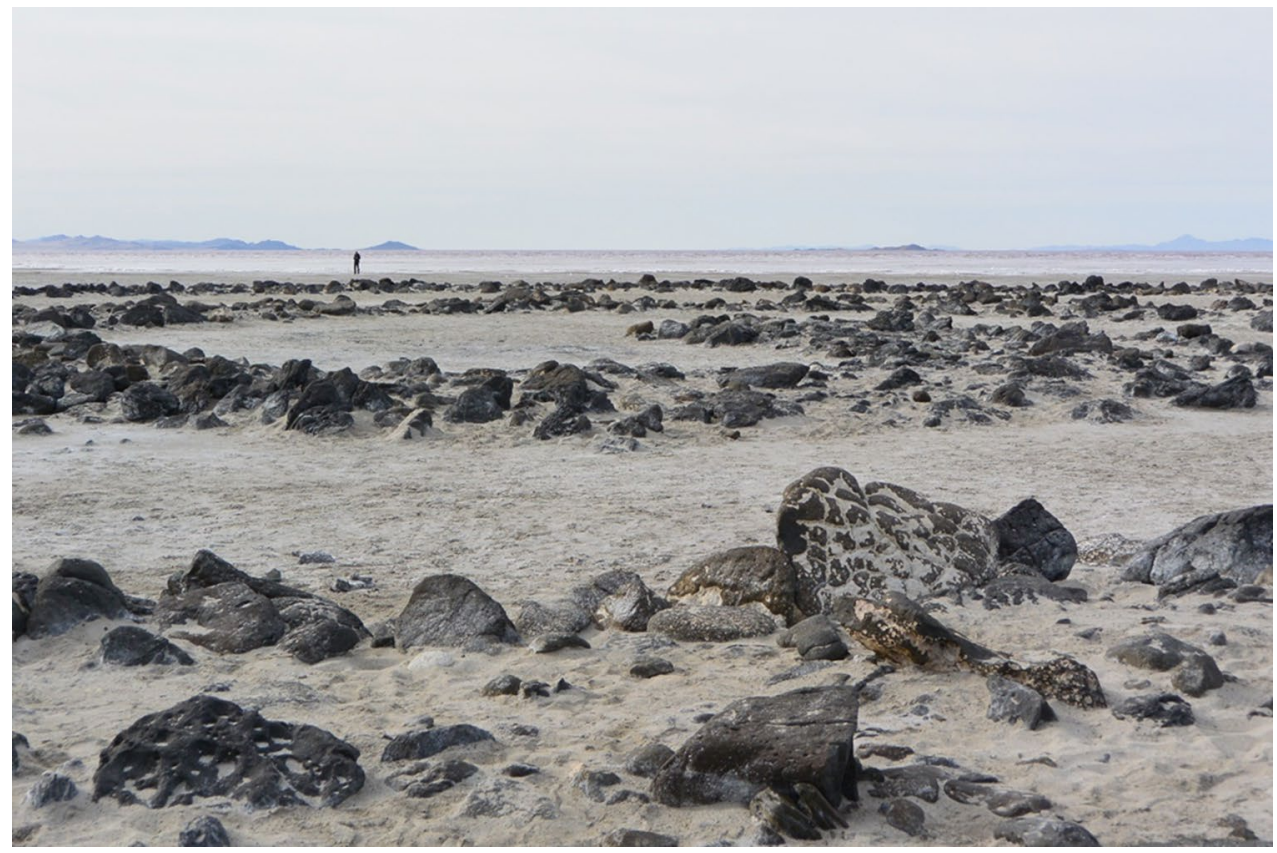

including LEED and SITES. The pilot projects plus those that GBCI has certified since 2016 provide tangible examples of how an application of ecosystem services can result in places that both function more efficiently and offer a fresh aesthetic. The system also builds on the ecological design and planning ideas of McHarg, Spirn, and John Tillman Lyle. Lyle (1994) believed sustainable design does not go far enough to address the environmental challenges human communities face. He advocated regenerative design. Lyle explained: "Regenerative design means replacing the present linear system of throughput flows at sources, consumption centers, and sinks" (1994, p. 10). And furthermore, "A regenerative system provides for continuous replacement, through its own functional processes, of energy and materials used in its operation" (1994, p. 10). What would such a regenerative system look like?

\section{The Prospects}

Meanwhile, Meyer (2008, 2016) offers a suggestion through her assertion that beauty is necessary to truly sustain landscapes. Meyer echoes Dewey in her connection of beauty "to the body and poly-sensual experience" (2008, p. 7). She observes that "beautiful sustainable landscape design involves the design of experiences much as the design of form and the design of ecosystems. These experiences are vehicles for connecting with, and caring for, the world around us" (Meyer 2008, p. 18).

A challenge then is to redefine beauty, that is, what gives pleasure to the senses and to the spirit. Ideas about beauty and aesthetics are always in flux, but in many ways, an engagement with nature, including human nature, underlies all great art. Laurie Olin has asserted that landscape design "derives, directly or indirectly, from nature and its processes, often translated through a series of abstractions and artistic expressions" (1988, p. 149). Designs produce places that exhibit aesthetics, and designers are conscious of those expressions. This underlies the need for an ecological aesthetic for today.

In physics, entropy involves the gradual decline of systems into disorder. Two months before his untimely death in 1973, the American artist Robert Smithson gave an interview, titled by the interviewer "Entropy Made Visible" (Sky 1973). Smithson discusses his preoccupation with entropy which clearly influenced his art, as is illustrated by his most famous work "Spiral Jetty" on the northern shore of the Great Salt Lake in Utah, USA. Smithson's framing of weathering and erosion processes is clear in this 1970 earthwork of black basalt rocks. Smithson's embrace of natural processes and entropy has had considerable influence on artists and designers (Fig. 1).

Negentropy is the opposite of entropy in which systems seek order (McHarg 1969, p. 53). The reversal of entropy requires considerable energy and imagination and is accompanied with risk. However, the potential rewards outweigh the costs. Ecologically based design and planning can be seen as tools of negentropy, means for human adaptation that emphasize organization, structure, and function that create order out of chaos. As Smithson underlined in his quest to make entropy visible, ecological aesthetics should enable us to see and to understand the processes of change. If ecology helps us to see the wounds 
of the world, then ecological aesthetics and its underlying wisdom suggest prospects for renewal and hope.

\section{References}

Austin N (2018) The virtue of ecophronesis: an ecological adaptation of practical wisdom. Heythrop J 2:1009-1021

Batty M, Marshall S (2017) Thinking organic, acting civic: the paradox of planning for cities in evolution. Landsc Urban Plan 166:4-14

Bourassa SC (1991) The aesthetics of landscape. Belhaven Press, London

Chatterjee A (2014) The aesthetic brain: how we evolved to desire beauty and enjoy art. Oxford University Press, Oxford

Dewey J (1934) Art as experience. Perigee, New York

Granger F (editor and translator) (1931) Vitruvius on architecture. Harvard University Press, Cambridge

Lady Bird Johnson Wildflower Center, the University of Texas at Austin, U.S. Botanic Garden, American Society of Landscape Architects (2014) SITES v2: reference guide for sustainable land design and development. Sustainable Sites Initiative, Austin

Leopold A (1939) The farmer as conservationist. In: Callicott B, Flader SL (eds) The river of the mother of god: and other essays by Aldo Leopold. University of Wisconsin Press, Madison

Leopold A (1949) A sand county almanac: and sketches here and there. Oxford University Press, Oxford

Leopold A (1966) Round river: from the journals of Aldo Leopold (Leopold LB, editor). Oxford University Press, Oxford

Lyle JT (1994) Regenerative design for sustainable development. Wiley, New York

McHarg IL (1969) Design with nature. Natural History Press, Garden City

Meyer E (2008) Sustaining beauty. The performance of appearance. A manifesto in three parts. J Landsc Archit 3(1):6-23

Meyer E (2016) Sustaining beauty: the performance of appearance. In: Steiner FR, Thompson GF, Carbonell A (eds) Nature and cities; the ecological imperative in urban design and planning. Lincoln Institute of Land Policy, Cambridge

Olin L (1988) Form, meaning, and expression in landscape architecture. Landsc J 7(2):149-168
Prigogine I, Stengers I (1984) Order out of chaos. Bantam, New York Prum RO (2017) The evolution of beauty: how Darwin's forgotten theory of mate choice shapes the animal world-and us. Doubleday, New York

Sachs A (2018) Environmental design: architecture, politics, and science in postwar America. University of Virginia Press, Charlottesville

Schrödinger E (1944) What is life? Cambridge University Press, Cambridge

Sky A (1973) "Entropy made visible" (interview with Robert Smithson). In: Flam J (ed) Robert Smithson: the collected writings, 1996. The University of California Press, Berkeley

Spirn AW (1998) The language of landscape. Yale University Press, New Haven

Steiner F, McSherry L (2017) Observation, reflection, action. Landsc Urban Plan 166:55-56

Windhager S, Steiner F, Simmons MT, Heymann D (2010) Toward ecosystem services as a basis for design. Landsc J 29(2):107-123

Woodruff SC, BenDor TK (2016) Ecosystem services in urban planning: comparative paradigms and guidelines for the high quality plans. Landsc Urban Plan 152:90-100

Xiang W-N (2016) Ecophronesis: the ecological practical wisdom for and from ecological practice. Landsc Urban Plan 155:53-60

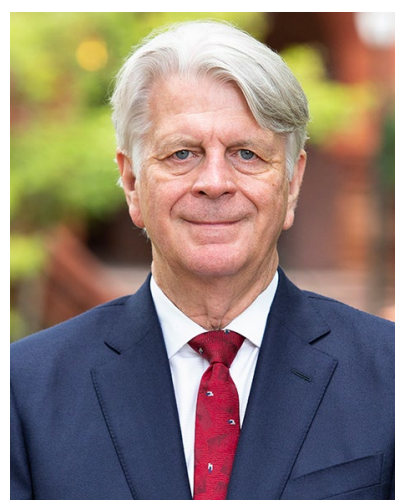

Frederick Steiner is dean and Paley Professor, and co-executive director of The Ian L. McHarg Center for Urbanism and Ecology, at the University of Pennsylvania School of Design. He has written, edited, or coedited 18 books, including Making Plans: How to Engage with Landscape, Design, and the Urban Environment. 